\title{
Experimental Investigation of Solder Joint Defect Formation and Mitigation in Reduced-Gravity Environments
}

\author{
J. Kevin Watson* \\ NASA Johnson Space Center, Houston, TX, 77058 \\ Peter M. Struk ${ }^{\dagger}$ \\ NASA Glenn Research Center, Cleveland, $\mathrm{OH}, 44135$ \\ and \\ Richard D. Pettegrew \\ Robert S. Downs ${ }^{\S}$ \\ National Center for Space Exploration Research, Cleveland, OH, 44135
}

This paper documents a research effort on reduced gravity soldering of plated through hole joints which was conducted jointly by the National Center for Space Exploration Research, NASA Glenn Research Center, and NASA Johnson Space Center. Significant increases in joint porosity and changes in external geometry were observed in joints produced in reduced gravity as compared to normal gravity. Multiple techniques for mitigating the observed increase in porosity were tried, including several combinations of flux and solder application techniques, and demoisturizing the circuit board prior to soldering. Results were consistent with the hypothesis that the source of the porosity is a combination of both trapped moisture in the circuit board itself, as well as vaporized flux that is trapped in the molten solder. Other topics investigated include correlation of visual inspection results with joint porosity, pore size measurements, limited pressure effects $(0.08$ $\mathrm{MPa}-0.1 \mathrm{MPa})$ on the size and number of pores, and joint cooling rate.

\section{Nomenclature}

$A=$ time-averaged magnitude of the three-dimensional acceleration

$A_{x}=$ magnitude of acceleration in the longitudinal axis of the aircraft

$A_{y}=$ magnitude of acceleration in the lateral axis of the aircraft

$A_{z}=$ magnitude of acceleration in the vertical axis of the aircraft

$\mathrm{C}_{\mathrm{P}}=$ specific heat of solder $(60 / 40 \mathrm{wt} \% \mathrm{Sn} / \mathrm{Pb})=173 \mathrm{~J} / \mathrm{kg}-\mathrm{K}^{1-3}$

$\mathrm{g}_{\mathrm{e}}=$ normal gravitational acceleration at sea level $\left(9.81 \mathrm{~m} / \mathrm{s}^{2}\right)$

$\mathrm{h}_{\mathrm{f}}=$ latent heat of solidification for solder $(60 / 40 \mathrm{wt} \% \mathrm{Sn} / \mathrm{Pb})=37,000 \mathrm{~J} / \mathrm{kg}^{1-3}$

$\mathrm{L}_{\mathrm{T}} \quad=\quad$ fillet leg length on the side of the joint to which the solder alloy was added (i.e. the "top")

$\mathrm{L}_{\mathrm{B}} \quad=$ fillet leg length on the side of the joint opposite to which solder alloy was added (i.e. the "bottom")

$\mathrm{m}=$ solder joint mass

$Q \quad=\quad$ total thermal energy of solder joint $(\mathrm{J})$

$\dot{Q}_{a v} \quad=\quad$ average thermal energy transfer rate from the solder joint (W)

$\mathrm{t} \quad=$ time $(\mathrm{s})$

$\mathrm{t}_{\mathrm{c}}=$ cooling time of solder joint from heating iron removal to solidification (s)

$\mathrm{T}_{\mathrm{P}} \quad=\quad$ measured peak solder temperature $(\mathrm{K})$

$\mathrm{T}_{\mathrm{M}}=$ solder $(60 / 40 \mathrm{wt} \% \mathrm{Sn} / \mathrm{Pb})$ melting temperature $=456 \mathrm{~K}^{1-3}$

\footnotetext{
* Aerospace Engineer, Exploration Office, Mail Code EX, 2101 NASA Road 1

${ }^{\dagger}$ Aerospace Engineer, Mail Code 110-3, 21000 Brookpark Road

‡ Associate Staff Scientist, Mail Code 110-3, 21000 Brookpark Road, AIAA Member

$\S$ Student Researcher, Mail Code 110-3, 21000 Brookpark Road
} 


\section{Introduction}

$\mathrm{W}$ hether used occasionally for contingency repair or routinely in nominal repair operations, soldering will become increasingly important to the success of future long-duration human space missions. As a result, it will be critical to have a thorough understanding of the service characteristics of solder joints produced in reducedgravity environments.

A limited amount of soldering has been performed onboard the Soviet/Russian Mir space station and, more recently, onboard the International Space Station (ISS) for contingency repairs. While no reports have been made of operational failure of such repaired joints, no formal testing (either destructive or non-destructive) has been performed to characterize the changes that a reduced gravity environment could have on such joints.

To date, a limited amount of experimental work has been conducted to assess the soldering process in reducedgravity environments. Gap filling and microstructure have been investigated on sounding rocket flights ${ }^{4}$. Test results showed that wider annular gaps between concentric copper tubes could be filled with solder in low gravity via capillary action compared with normal gravity conditions. In normal gravity, the molten solder alloy tended to accumulate in the lower portion of the annulus. An observed increase in the $\mathrm{Cu}-\mathrm{Sn} \mathrm{h}$ phase was attributed to slightly discrepant thermal cycles rather than to gravitational influences. Several Get Away Special payloads were flown on the Shuttle between 1982 and $1984^{5-6}$. Although the success of these efforts was mixed, they demonstrated the influence of surface tension on the soldering process. Additionally, the potential for flux entrapment in the solder joints because of the lack of buoyancy force was suggested but not confirmed ${ }^{5}$. Jones and deRooij ${ }^{7}$ reported that there was no observed difference between solder joints produced in reduced-gravity on a research aircraft and under normal 1-g conditions from the standpoint of internal microstructure. They did not, however, report on other functional characteristics of the solder joints.

A manual soldering test was performed on Shuttle mission STS-57 in 1993. In this test a variety of types of solder joints were produced. Although there was no report of detailed analysis on the characteristics of these samples, the success of this test was sufficient to warrant manifesting a soldering kit on ISS for contingency repairs.

To gain confidence in the reliability of soldering as a standard repair process for space missions, we conducted a more detailed assessment of the important service-related characteristics of solder joints produced in low-gravity. As a preliminary step in this effort, beginning in 2001, we conducted a series of reduced-gravity soldering tests utilizing NASA's KC-135 research aircraft. The testing involved 8 flight weeks and spanned over 3 years, using a plated through-hole (PTH) configuration. Results of these tests characterized changes in the solder joints, including geometric changes and increases in internal porosity as a result of the reduced gravity environment. The sources of the increased porosity appear to be flux vapor which was trapped in the molten solder, and entrapped moisture in the circuit board itself. Several techniques were tested to mitigate the porosity increase, including alternate techniques for flux application and demoisturization of the circuit board prior to soldering.

\section{Experimental Procedure}

Soldering operations took place onboard NASA's KC-135 reduced gravity research aircraft. This aircraft flies repeated parabolic trajectories yielding 20 - 30 second periods of reduced gravity of approximately $10^{-2}$ ge (where 1$\mathrm{g}_{\mathrm{e}}$ is the normal gravitational acceleration of about $9.8 \mathrm{~m} / \mathrm{s}^{2}$ experienced at sea level). This aircraft is also capable of flying modified parabolic trajectories that yield partial-g environments such as those experienced on the surface of the moon or Mars. Although most reduced-g samples in this project were produced in a nominal $10^{-2} \mathrm{~g}_{\mathrm{e}}$ environment, a limited number were produced at accelerations of 0.1-ge, 0.17-ge (lunar), 0.25-ge, and 0.38-ge (Mars). The actual acceleration achieved onboard the aircraft may not be precisely the nominal value and is also subject to irregular disturbances from pilot control inputs, atmospheric buffeting, and other sources. During each parabola, the Space Acceleration Measurement System (SAMS) hardware, located on our experiment, measured and recorded the acceleration at $100 \mathrm{~Hz}$ in the three primary orthogonal axes of the aircraft. ${ }^{8}$. The quality of each parabola was assessed in terms of disturbances to the reduced-gravity environment ${ }^{9}$. Baseline samples soldered under 1-ge conditions were made in the experimental hardware on the aircraft - both on the ground (atmospheric pressure approximately $0.10 \mathrm{MPa}$ ) and in flight at a cabin pressure of roughly $0.08-0.09 \mathrm{MPa}$.

Manual soldering was performed on samples composed of $1 / 2$-watt carbon resistors mounted to the PTH printed circuit board (PCB). The soldering iron is a Weller ${ }^{\circledR}$ model TCP 12P with a PTP7 tip and is the same model as currently flown in the soldering kit aboard the ISS. The same PCB configuration (Fig. 1) was used throughout the tests; however, two different resistor diameter leads $(0.66 \mathrm{~mm}$ and $0.78 \mathrm{~mm} \pm 0.04 \mathrm{~mm})$ were used. Prior to soldering, the samples were prepared (e.g. cleanliness, tinning, etc.) according to the NASA standard for electrical connections $^{10}$. However, only some of the boards were demoisturized (by an oven bake) prior to soldering. The resistors and PCBs were pre-assembled - with the resistors held in position by a silicon rubber adhesive. Resistor 
leads, which were tinned with solder $(60 / 40 \mathrm{wt} \% \mathrm{Sn} / \mathrm{Pb})$, were inserted through a $1.33 \mathrm{~mm}$ diameter plated-throughhole. For each joint, solder wire was pre-cut and weighed before and after soldering to estimate the mass added to each joint. The soldering of all samples was videotaped with sufficient resolution to observe the details of soldering such as pre- and post-heat times as well as solidification. In some cases, pre- and post- heat times were controlled. A pressure transducer provided ambient pressure measurements and select samples were instrumented with thermocouples providing temperature measurements during the soldering process. Additionally, a relative humidity reading was manually recorded during soldering for a significant portion of the tests. More detail of the experimental hardware is provided elsewhere ${ }^{11-12}$.

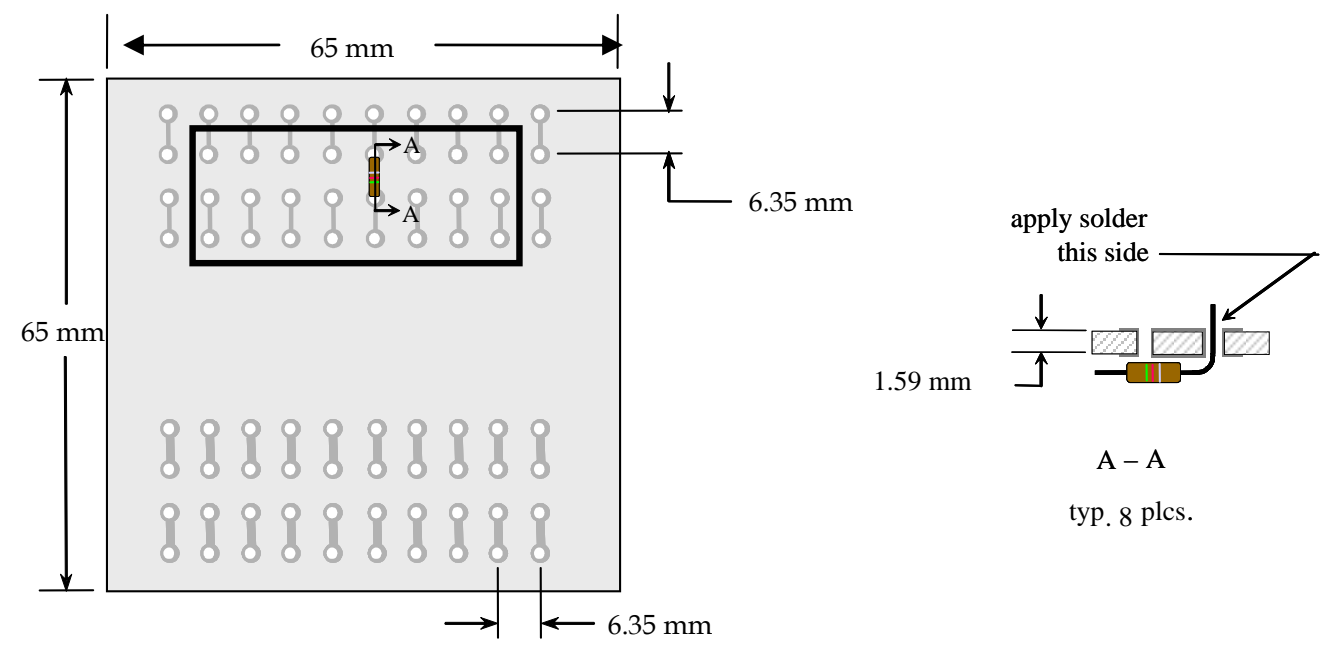

Fig. 1 Sample configuration. All dimensions are approximate.

For reasons to be discussed later, several variations of the soldering procedure were tested. These included:

1. $60 / 40 \mathrm{wt} \% \mathrm{Sn} / \mathrm{Pb}$ rosin core solder, PCBs in as-received condition from the manufacturer.

2. $60 / 40 \mathrm{wt} \% \mathrm{Sn} / \mathrm{Pb}$, rosin core solder, PCBs baked at least 4 hours at $93 \mathrm{C}$ and subsequently kept in a dry environment prior to soldering.

3. $60 / 40 \mathrm{wt} \% \mathrm{Sn} / \mathrm{Pb}$, solid solder, externally applied liquid flux (Multicore 6381-25), PCBs in as-received condition.

4. 60/40 wt\% $\mathrm{Sn} / \mathrm{Pb}$, solid core, externally applied gel flux (Kester RF-741), PCBs in as-received condition.

Seven individuals performed the soldering operations. These personnel were provided with training to assure a common base level of knowledge and experience. Two of the individuals are certified for soldering of spaceflight hardware per NASA standards and, thus, were considered to be "experts". This provided a range of skill levels, from 'trained-novice' through expert, such as may be encountered on a flight crew.

Following cleaning of residual surface flux, all samples were visually inspected (pass/fail) to the applicable NASA standard ${ }^{10}$. Additional post-soldering evaluation of the samples included geometrical measurements and metallographic cross-sectioning and examination. More detail is provided in following section.

The primary macroscopic geometrical characteristic of interest was fillet leg length, as defined in Fig. 2a. The values of the vertical leg lengths were measured from images of the sample profiles prior to cross-sectioning. The vertical fillet leg length on the side of the joint to which the solder alloy was added (i.e. the "top") was designated as $\mathrm{L}_{\mathrm{T}}$. Conversely, the fillet leg length on the other side of the PCB (i.e. the "bottom") was designated as $\mathrm{L}_{\mathrm{B}}$.

The subsequently cross-sectioned fillets revealed features of interest that were visible without additional processing. Cross-sections were photographed at approximately 20X magnification (Fig. 2b). Internal porosity (or void content), as a percentage of cross-sectional area, was determined by digitizing the photographs (Fig. 2c) and electronically designating the voids (the area shown in gray) and the entire area of solidified solder alloy (the sum of the areas shown in gray and white). This procedure and the subsequent data analysis are in accordance with ASTM Standard E1245- $00^{13}$. 


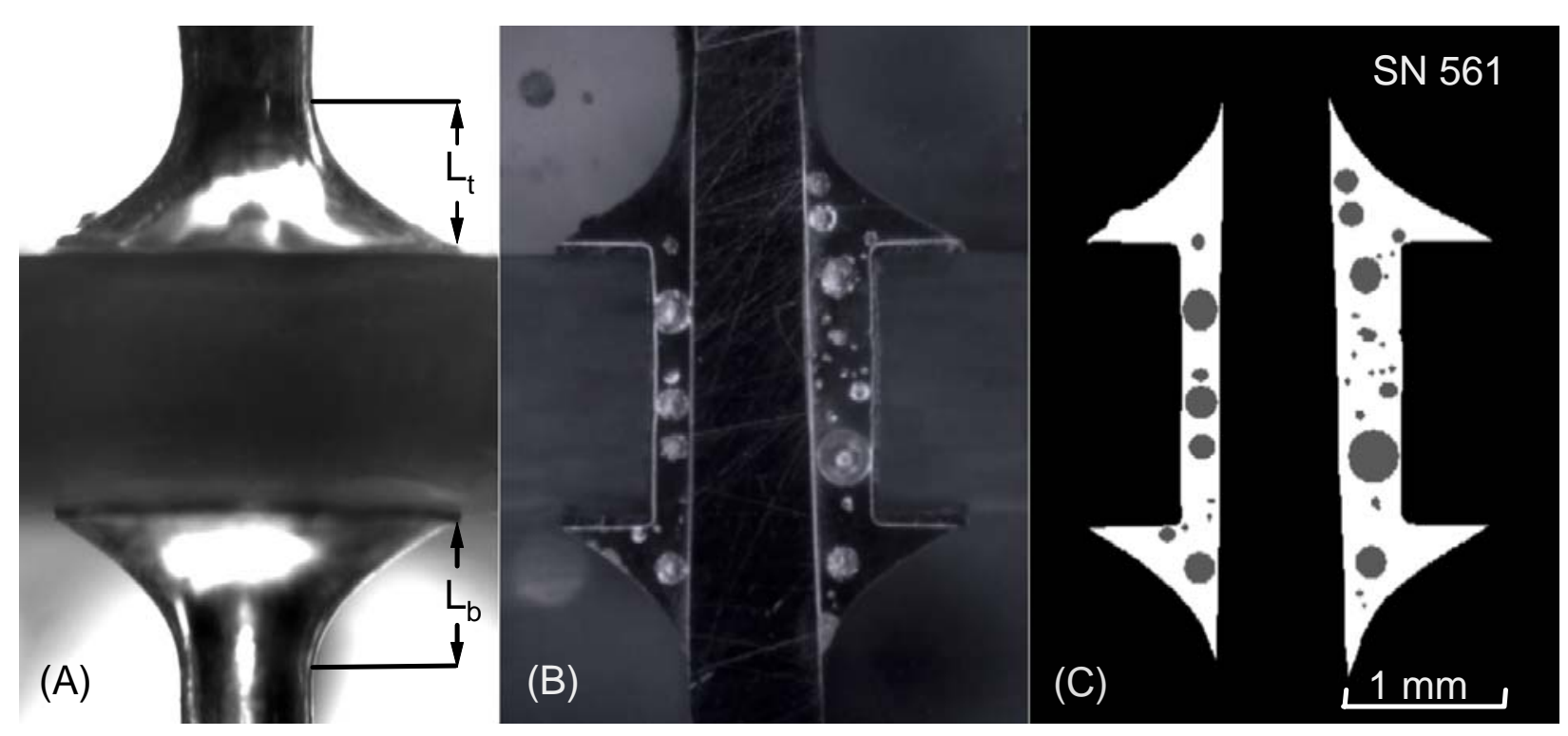

Fig. 2 (a) Image of joints after soldering in reduced gravity, (b) after cross-sectioning, and (c) after computer analysis. Solder was applied to the joint from the top of solder joint as orientated in the images. This joint shows significant sub-surface voids.

\section{Results And Discussion}

To date, we have generated 1347 solder samples in the plated through-hole (PTH) configuration, including 938 low-gravity samples (with some partial-gravity samples) and 409 normal-gravity samples. Two different resistor lead diameters were used in the experiment: $0.66 \mathrm{~mm}$ and $0.78 \mathrm{~mm}$. The varying lead diameters produce different gap widths for the solder to flow through. This varying gap width may affect the capillary forces that move the fluid in microgravity. For the present analysis, however, we did not differentiate samples with different resistor lead diameters.

\section{A. Acceleration Environment}

The acceleration experienced onboard the aircraft is subject to a variety of changing conditions. These include irregular low frequency, high amplitude disturbances from pilot control inputs, atmospheric buffeting, and other sources, as well as high frequency, low amplitude vibrations (termed ' $g$-jitter') from airframe and engine vibrations. These undesired accelerations cause both low and high frequency oscillations about the targeted acceleration level. A recent paper, which describes the acceleration environment and measurements in detail, investigated the influence of 'g-jitter' on the soldering process - particularly porosity'. Based on results of this paper, we established an acceptance criterion of $A £ 0.02 \mathrm{~g} / \mathrm{g}_{\mathrm{e}}$ during the time when the solder was molten. The equation used to compute A is shown in Eq. 1 and represents the time-averaged magnitude of the three-dimensional acceleration for each parabola using the Root-Sum-Square (RSS) method. In Eq. 1, the symbols $A_{x}, A_{y}$, and $A_{z}$ are the magnitude of acceleration in the longitudinal, lateral, and vertical axes of the aircraft, respectively, while t represents time. An example of the acceleration data obtained during a test is shown in Fig. 3. The horizontal lines on each graph denote acceleration values of $\pm 0.02 \mathrm{~g} / \mathrm{g}$ e while the vertical lines denote events during the soldering process which are labeled in the figure. In Fig. 3, the solder is molten from $t_{1}$ to $t_{2}$ and the integration in Eq. 1 yields an acceptable parabola with the value of A being $0.02 \mathrm{~g} / \mathrm{g}_{\mathrm{e}}$. With the exception of leg-length data (Table 8), all nominally 0 -ge data presented only include cases which passed the g filter (i.e. A $£ 0.02 \mathrm{~g} / \mathrm{g}_{\mathrm{e}}$ ). The acceleration filter had minimal impact on the leg-length data and was consequently unfiltered. Finally, partial gravity parabolas (i.e. 0.1-ge, lunar $0.17-g_{e}$, or Martian - $0.38 \mathrm{ge}_{\mathrm{e}}$ ) were also unfiltered.

$$
A=\frac{1}{t_{2}-t_{1}} \int_{t_{1}}^{t_{2}} \sqrt{A_{x}^{2}(t)+A_{y}^{2}(t)+A_{z}^{2}(t)} d t
$$




\section{B. Visual Examination}

All samples were visually inspected to the applicable NASA standard $^{10}$. Results of the visual inspection are presented in Table 1 . The causes for failure during the inspection have been categorized as either "Surface Porosity" or "Workmanship." In this context the term "surface porosity" includes any feature that is indicative of porosity in the solder joint. Examples would include pores or pinholes obviously open to the surface, cavities interpreted as being collapsed bubbles, and bulges or spikes interpreted as being closed bubbles manifested at the surface. The term "workmanship" includes lack of wetting of the solder alloy, lack of flow-through of solder alloy from the side of the joint to which it is applied to the other side, insufficient or excess solder, indications of overheating, or visible contaminants. The data in Table 1 indicate that a larger percent of joints failed due to surface porosity across all conditions in $0-\mathrm{g}_{\mathrm{e}}$ when compared to $1-\mathrm{g}_{\mathrm{e}}$. The data suggest that there is a lower incidence of workmanship failures for samples produced in 0 -ge compared to those produced in $1-\mathrm{g}_{\mathrm{e}}$. Finally, no noteworthy differences were seen in the quality of samples produced by the experienced soldering technician compared with the samples produced by less-experienced personnel. This was true for both the visual inspection failures presented here and also the quantity of porosity which is discussed in the next section.

\section{Internal Porosity}

1. Volume fraction of porosity as a function of g-level for plated through hole $(\mathrm{PTH})$ soldering

Joint porosity is defined as the

ratio of 2-D areas designated as voids (shown in gray in Fig. 2c) to the 2-D imaged area of solidified solder alloy (white and gray areas). The relationship between a void volume fraction measured at one planar location and the volume fraction of the entire joint may not be valid for any single joint, unless the voids are uniformly distributed throughout the joint. However, large population statistics (i.e., planar measurements over many joints) can reasonably represent the average nature of the void distribution throughout the joint ${ }^{13}$.

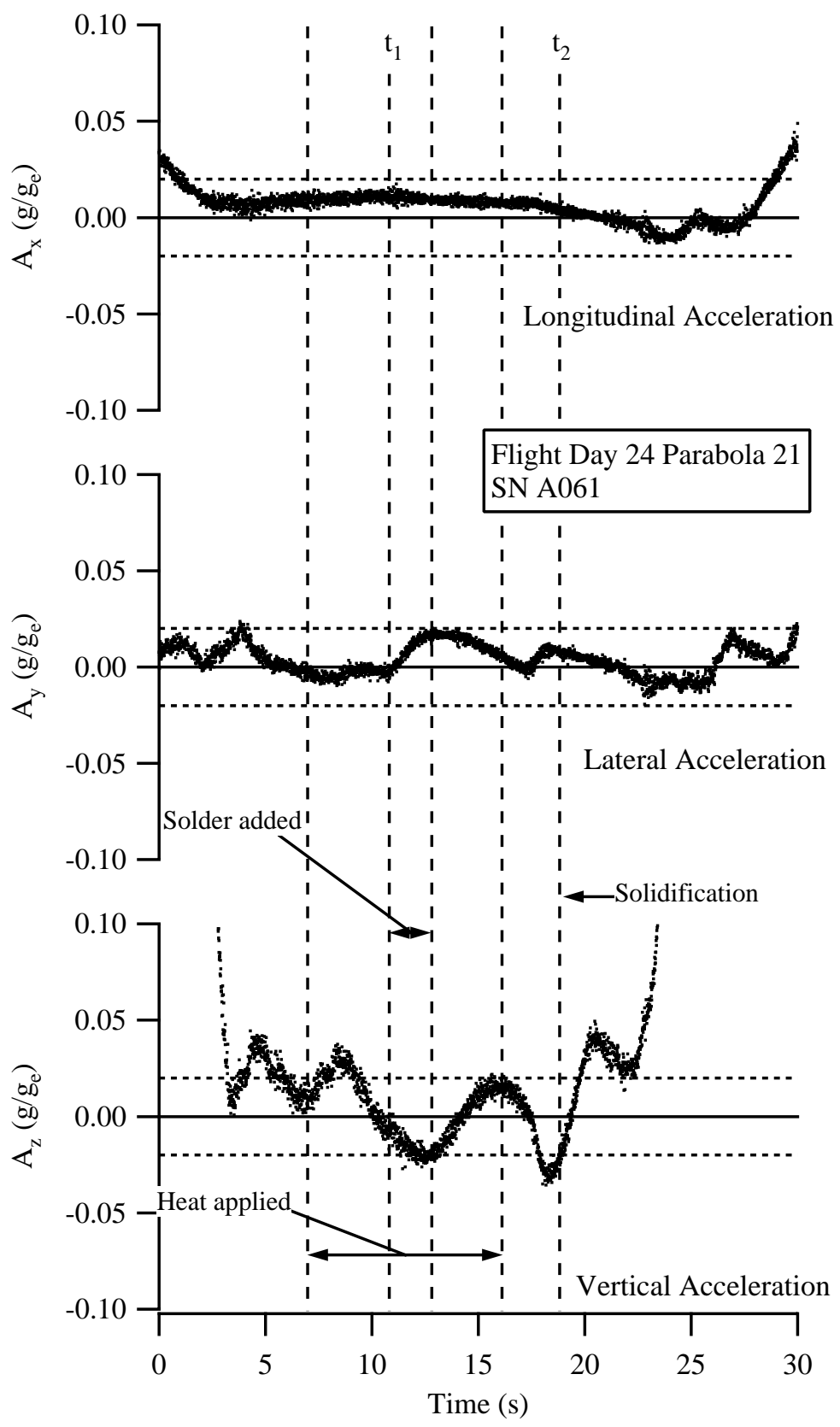

Fig. 3 Acceleration data from the SAMS 3-axis accelerometer taken while soldering a PTH joint during a targeted 0 -g $_{e}$ parabola (Struk et al, 2004). 
Table 1 Percentage of samples failing visual inspection for each test condition.

\begin{tabular}{|c|c|c|c|c|c|}
\hline \multirow{2}{*}{ Soldering Conditions } & \multirow{2}{*}{$\begin{array}{c}\text { Total } \\
\text { samples } \\
1-g_{e} / 0-g_{e}\end{array}$} & \multicolumn{2}{|c|}{$\begin{array}{l}\text { Surface Porosity } \\
\% \text { failed (\# failed) }\end{array}$} & \multicolumn{2}{|c|}{$\begin{array}{c}\text { Workmanship } \\
\text { \% failed (\# failed) }\end{array}$} \\
\hline & & $1-g_{e}$ & $0-g_{e}$ & $1-g_{e}$ & $0-g_{e}$ \\
\hline Flux-core solder & $102 / 77$ & $11.8 \%(12)$ & $19.5 \%(15)$ & $5.9 \%(6)$ & $7.8 \%(6)$ \\
\hline Solid solder - liquid flux & $111 / 153$ & $5.4 \%(6)$ & $15.0 \%(23)$ & $12.6 \%(14)$ & $7.2 \%(11)$ \\
\hline Solid solder - gel flux & 32 / 43 & $9.4 \%(3)$ & $44.2 \%(19)$ & $15.6 \%(5)$ & $2.3 \%(1)$ \\
\hline Flux-core solder, baked PCB & $56 / 102$ & $0.0 \%(0)$ & $4.9 \%(5)$ & $16.1 \%(9)$ & $2.0 \%(2)$ \\
\hline
\end{tabular}

Fig. 4 shows a plot of the cumulative fraction of samples that have a given porosity or less. The data in Fig. 4 compare joints that were formed in near 0 g $_{\mathrm{e}}$ to those formed in $1-\mathrm{g}_{\mathrm{e}}$ using flux-cored solder. For example, this plots shows that $80 \%$ of the normal gravity samples have roughly $4 \%$ or less porosity, while only about $33 \%$ of the low-g samples have similar porosity.

A limited number of samples were produced in partial gravity environments. The acceleration environment for these tests were nominally at $0.10 \mathrm{~g} / \mathrm{g}_{\mathrm{e}}, 0.17 \mathrm{~g} / \mathrm{g}_{\mathrm{e}}$ (Lunar), or $0.38 \mathrm{~g} / \mathrm{g}_{\mathrm{e}}$ (Martian), \pm approximately $0.02 \mathrm{~g} / \mathrm{g}_{\mathrm{e}}$ for each case. The sample populations were small for each test, both because of the limited number of partial-g parabolas performed on each flight (typically, a maximum of 5-10 of the $\sim 40$ parabolas per flight are flown in a partial-g profile, if any), and because the number of available partial-g parabolas was divided between different soldering techniques. These tests were mainly conducted using flux-core solder with PCBs in either as-received condition or baked, though a small number were tried with solid solder and liquid flux.

Table 2 shows the porosity data from the partial gravity tests, along with results from (nominally) $0-\mathrm{g}_{\mathrm{e}}$ tests, for comparison. The 95\% confidence intervals on the mean values were not computed for the partial gravity datasets due to the comparatively small populations. The small number of samples in each given condition precludes meaningful statistical comparisons of the partial-g results, but the general trend (with regard to the mean porosity percentage) suggests the expected result that porosity increases as the acceleration levels decrease. Further testing at these conditions would be required to develop a dataset of sufficient size to draw

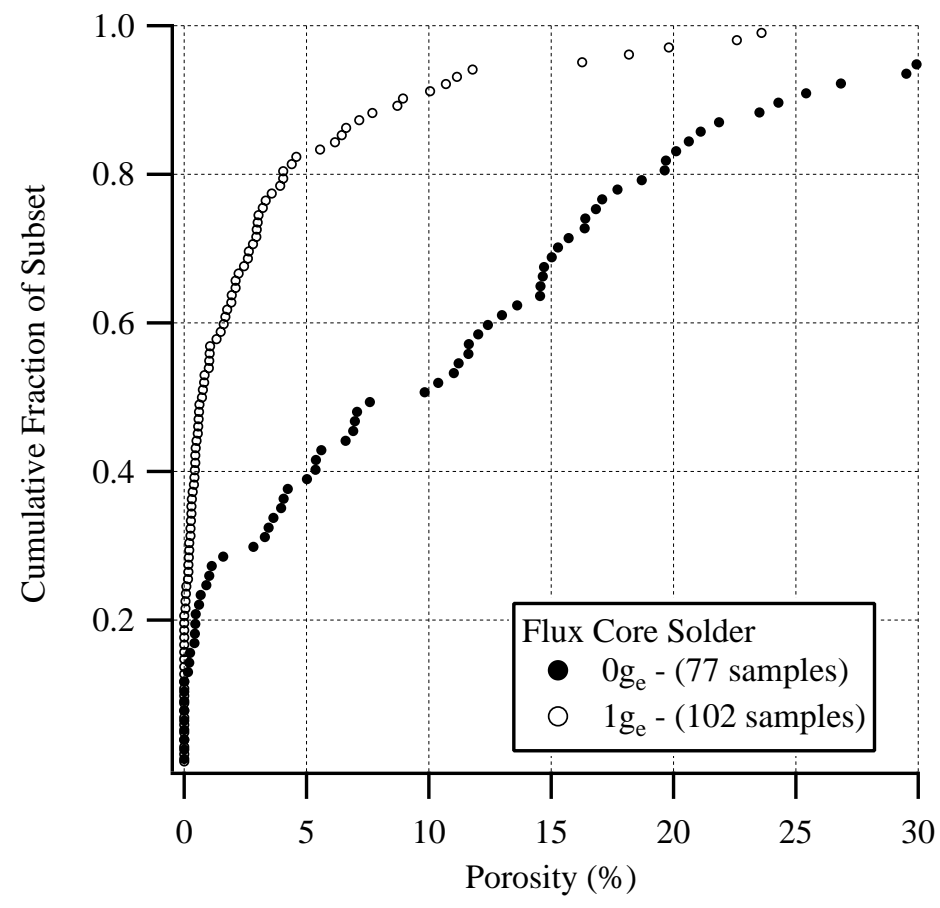

Fig. 4 Cumulative distribution function for porosity of fluxcored solder joints. (Struk et al, 2004). 
Table 2. Mean porosity values for partial gravity samples.

\begin{tabular}{|c|c|c|c|c|c|}
\hline Test Condition & $0-g_{e}$ & $0.10-g_{e}$ & $\begin{array}{l}\text { 0.17-ge } \\
\text { (Lunar) }\end{array}$ & $\begin{array}{c}\text { 0.38-ge } \\
\text { (Martian) }\end{array}$ & $1-g_{e}$ \\
\hline Flux-core solder & $\begin{array}{c}11.0 \pm 2.38 \% \\
77 \text { samples } \\
\end{array}$ & $\begin{array}{c}9.27 \% \\
11 \text { samples } \\
\end{array}$ & $\begin{array}{c}7.75 \% \\
16 \text { samples } \\
\end{array}$ & $\begin{array}{c}5.41 \% \\
18 \text { samples } \\
\end{array}$ & $\begin{array}{c}3.21 \pm 1.17 \% \\
102 \text { samples } \\
\end{array}$ \\
\hline $\begin{array}{l}\text { Solid solder - liquid } \\
\text { flux }\end{array}$ & $\begin{array}{c}6.64 \pm 1.24 \% \\
153 \text { samples }\end{array}$ & $\mathrm{n} / \mathrm{a}$ & $\begin{array}{c}6.44 \% \\
7 \text { samples }\end{array}$ & $\begin{array}{c}8.53 \% \\
7 \text { samples }\end{array}$ & $\begin{array}{c}2.75 \pm 0.64 \% \\
111 \text { samples }\end{array}$ \\
\hline Solid solder - gel flux & $\begin{array}{c}10.5 \pm 2.40 \% \\
43 \text { samples }\end{array}$ & $\mathrm{n} / \mathrm{a}$ & $\mathrm{n} / \mathrm{a}$ & $\mathrm{n} / \mathrm{a}$ & $\begin{array}{c}3.44 \pm 1.57 \% \\
32 \text { samples }\end{array}$ \\
\hline $\begin{array}{l}\text { Flux-core solder, baked } \\
\text { PCB }\end{array}$ & $\begin{array}{c}6.32 \pm 1.40 \% \\
102 \text { samples }\end{array}$ & $\begin{array}{c}1.43 \% \\
5 \text { samples }\end{array}$ & $\begin{array}{c}3.80 \% \\
5 \text { samples }\end{array}$ & $\begin{array}{c}5.47 \% \\
10 \text { samples }\end{array}$ & $\begin{array}{c}2.78 \pm 1.54 \% \\
56 \text { samples }\end{array}$ \\
\hline
\end{tabular}

\section{Causes and impact of porosity}

Porosity in solder joints likely comes from entrapped gasses which are composed of vaporized flux and/or water vapor. A decrease in gravity reduces the buoyancy force allowing fewer bubbles to escape to the surface. Previous analysis has suggested that the small bubbles in solder reach their terminal velocity within milliseconds ${ }^{9}$. This same analysis shows that for a typical bubble with a radius of $0.075 \mathrm{~mm}$ the terminal velocity drops from $6 \mathrm{~mm} / \mathrm{s}$ in $1 \mathrm{~g}_{\mathrm{e}}$ to $0.1 \mathrm{~mm} / \mathrm{s}$ at $0.02 \mathrm{ge}$. This implies that for distances characteristic of the samples used in this experiment and for the periods of time for which the solder is molten, there is likely inadequate time for the majority of pores to move to a free surface and dissipate. Further, since the disturbances to the gravitational environment onboard the aircraft have a variable direction, bubble motion will not be steady in one direction for the total available time but, rather, will be briefly in one direction then in another. This type of motion is believed to promote retention of bubbles. Bubble motion is expected to be even slower in true microgravity environments aboard spacecraft, thus further promoting bubble retention.

Consistent with the results reported here, recent experiments performed by the Imperial College of London on a research aircraft with a Sn-Ag-Cu eutectic solder alloy showed large increases in volume fraction of porosity in samples produced in $0-\mathrm{g}_{\mathrm{e}}$ compared with those produced in 1- $\mathrm{g}_{\mathrm{e}}-$ also attributed to lack of buoyant forces on bubbles formed by vaporized flux ${ }^{14}$. Mechanical testing of the $0-\mathrm{g}_{\mathrm{e}}$ samples yielded a shear strength of $15.5 \pm 2$ $\mathrm{MPa}$ - almost 30\% less than the $22 \mathrm{MPa}$ demonstrated by samples produced in 1-ge. Thus, it is important to develop techniques to mitigate the increase of porosity in reduced gravity.

The second most likely source of the gas that produced the porosity (following the solder flux) is absorbed moisture within the PCB material that diffuses through the plating on the surface of the hole and into the liquid solder alloy. It is known that epoxy-glass laminate materials used for PCB substrates can absorb significant amounts of moisture even under conditions of modest temperature and humidity ${ }^{15}$. This absorbed moisture has been credited as a source of porosity in solder joints ${ }^{16}$.

\section{Porosity Mitigation Techniques}

Since both entrapped flux and moisture evolved from the PCB are potential sources of porosity, experiments were performed to explore alternative fluxing techniques in an effort to reduce porosity and to assess the contribution to porosity from moisture. The first porosity mitigation technique tested was to apply a liquid flux (Multicore 6381-25) to the joint, heat the joint for sufficient time (discussed subsequently) to activate the flux and allow a significant amount of it to dissipate, and then apply the solid-core solder alloy before re-oxidation of the joint. A slight modification of this technique was to employ a gel flux (Kester RF-741) rather than the liquid flux. We believed that the gel flux might be easier to apply to the joint in operational on-orbit conditions. To maximize the available time for soldering, we applied the solder flux during the 2-ge pull-up just prior to the reduced gravity portion of a parabola on the KC-135 aircraft. The application of flux during 2-ge allowed the flux to preferentially move through the through-hole. We did a limited number of flux-application tests in $0-\mathrm{g}_{\mathrm{e}}$ and observed that flux was drawn though the through-hole sufficiently for our geometry and wetted the bottom side of the solder pad (although not in as great a quantity as seen in $2-\mathrm{g}_{\mathrm{e}}$ ). 


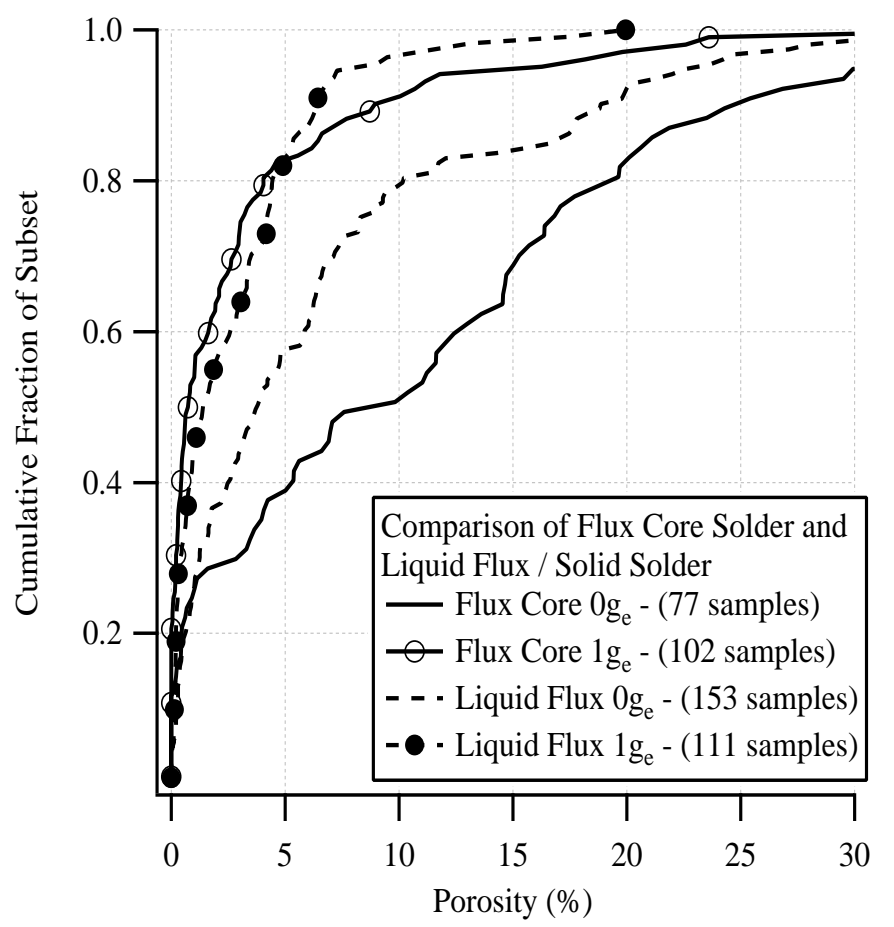

Fig. 5 Cumulative distribution function for porosity of joints soldered with solid solder and liquid flux compared to that of flux-cored solder joints

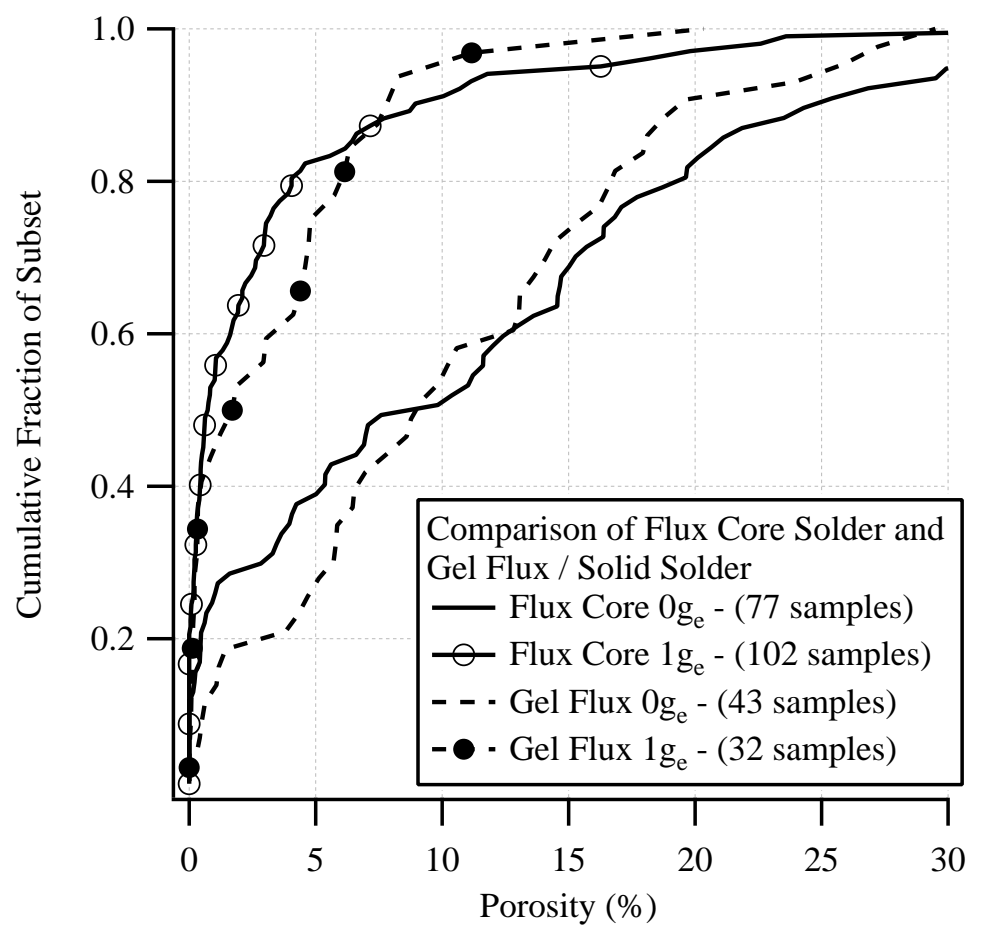

Fig 6. Cumulative distribution function for porosity of joints soldered with solid solder and gel flux compared to that of fluxcored solder joints
During a portion of the testing, we loosely controlled the pre- and post- heat durations. This was done to see if we would observe any changes in joint porosity and perhaps ascertain optimum pre- and post- heat durations. Finally, select PCBs were baked and kept in a desiccated environment prior to soldering to assess the effect of absorbed circuit board moisture on joint porosity.

\section{Liquid flux with solid-core solder}

The cumulative distribution functions for samples produced with externally applied liquid flux and solid solder wire are shown in Fig. 5. Included in this figure, for comparison, are the cumulative distribution functions for samples produced with conventional flux-cored solder.

From this figure it can be seen that for samples produced under 1 -g acceleration, the two soldering methods yielded similar results. At reduced acceleration, however, the samples produced with externally applied liquid flux contained significantly less porosity than samples produced with flux-cored solder.

\section{Gel flux with solid core solder}

The cumulative distribution functions for samples produced with externally applied gel flux and solid solder wire are shown in Fig. 6. Included in this figure, for comparison, are the cumulative distribution functions for samples produced with conventional flux-cored solder.

Again, it is evident that for samples produced under 1-g acceleration, the two soldering methods yielded similar results. At reduced acceleration, however, the samples produced with externally applied gel flux are only marginally better than samples produced with flux-cored solder. This suggests that, at least for this specific gel flux, the technique employed did not result in sufficient dissipation of the flux to substantially reduce porosity. 


\section{Effect of pre- and post-heat time}

During portions of the experiment, we loosely controlled the pre- and post-heating times. Nominally, we chose both pre- and post-heat intervals of 3 and 6 seconds which we deemed as optimal and slightly excessive, respectively. Although pre- and post-heat times were not precisely controlled, actual heating times for each test were extracted through video analysis. Data from tests where the timing was not specifically controlled but did fall into a desired interval were included in the subsequent analysis.

For cases of externally applied flux, we believed that variations in pre-heat time might influence joint porosity. For example, we conjectured that in a case of low pre-heating not all of the flux would be vaporized and consequently a larger porosity might occur. Based on the heating time distributions for the $0-\mathrm{g}_{\mathrm{e}}$ samples with externally applied flux, we generated 2 datasets for comparison: those with pre-heating of $3 \pm 1$ seconds and $7 \pm 1$ seconds. For pre-heat time comparison, the datasets were restricted to samples where the post-heat time is in the range of $3 \pm 1$ second. The intent was to isolate any effects of the pre-heat time by holding the post-heat time quasiconstant. The results for this analysis are summarized in Table 3. These results show no statistical difference between the selected pre-heat times.

Table 3. Effect of pre-heat duration on joint porosity in 0-g conditions.

\begin{tabular}{l|c|c}
\hline \hline \multirow{3}{*}{ Soldering Conditions } & Pre-heat: $3 \pm 1 \mathrm{~s}$. & Pre-heat $7 \pm 1 \mathrm{~s}$. \\
& Post-heat: $3 \pm 1 \mathrm{~s}$. & Post-heat: $3 \pm 1 \mathrm{~s}$. \\
\cline { 2 - 3 } & Porosity (samples) & Porosity (samples) \\
\hline Solid solder - liquid flux & $6.43 \pm 2.86(28)$ & $6.18 \pm 4.57(14)$ \\
\hline Solid solder - gel flux & $10.89 \pm 4.39(10)$ & $10.19 \pm 4.53(16)$ \\
\hline \hline
\end{tabular}

We investigated several other groupings of pre- and post-heat times in both 0 -ge and 1-ge, however, no clear effect on the sample porosity emerged. In most cases, the number of samples in the data subsets was low, resulting in rather large uncertainty. In the cases where the data subsets contain a larger number of samples, we observed no statistical difference in the porosity values as a result of pre-heat or post-heat time variations in this experiment.

\section{Printed circuit board moisture removal}

The question arises as to why there is porosity in 1-g samples if buoyancy is truly effective in causing bubbles to move to a free surface and be expelled. The likely answer is related to the sources of porosity and heating time. The introduction of flux ends either before the application of the alloy (in the case of the externally applied flux) or concurrently with the end of introduction of alloy (in the case of flux-cored wire). There follows a period of continued heating with the soldering iron to ensure distribution of the solder alloy and a period of progressive solidification. During this time the bubbles within the molten metal arising from vaporized flux can move to free surfaces and dissipate. The other source of porosity is the moisture that evolves from the PCB laminate ${ }^{15}$. For the soldering period, evolved moisture is probably a somewhat continuous source - introducing porosity into the solder alloy throughout the time during which it is molten. It is probable that moisture introduced into the molten alloy immediately prior to solidification does not have adequate time to move to the free surfaces and is trapped within the joint.

To remove entrapped moisture, select PCBs were baked prior to soldering as per NASA-STD-8739.3. This process required baking the PCB at a temperature of $93^{\circ} \mathrm{C}$ for a minimum of four hours. The PCBs for this experiment were typically baked overnight for a period of approximately 16 hours. Measurements of the PCB mass were made before and after the demoisturization process. These measurements indicated that the average mass lost per board was $0.036 \pm 0.003$ grams where the error bar represents one standard deviation. For an average board mass of 14.5 grams, this represents a $0.25 \%$ decrease in mass as a result of the demoisturization process. The likely source of this lost mass is absorbed water in the laminate material of the PCB (although strictly speaking we did not rule out the possibility of some other material evolving from the laminate). We performed a test wherein demoisturized PCBs were stored in environments of different relative humidity. The results of this test showed that a PCB exposed to normal room humidity ( $40 \%$ ) regained only about $8 \%$ of its lost mass in 20 minutes which is roughly the maximum duration a board would be removed from the desiccated environment prior to soldering 


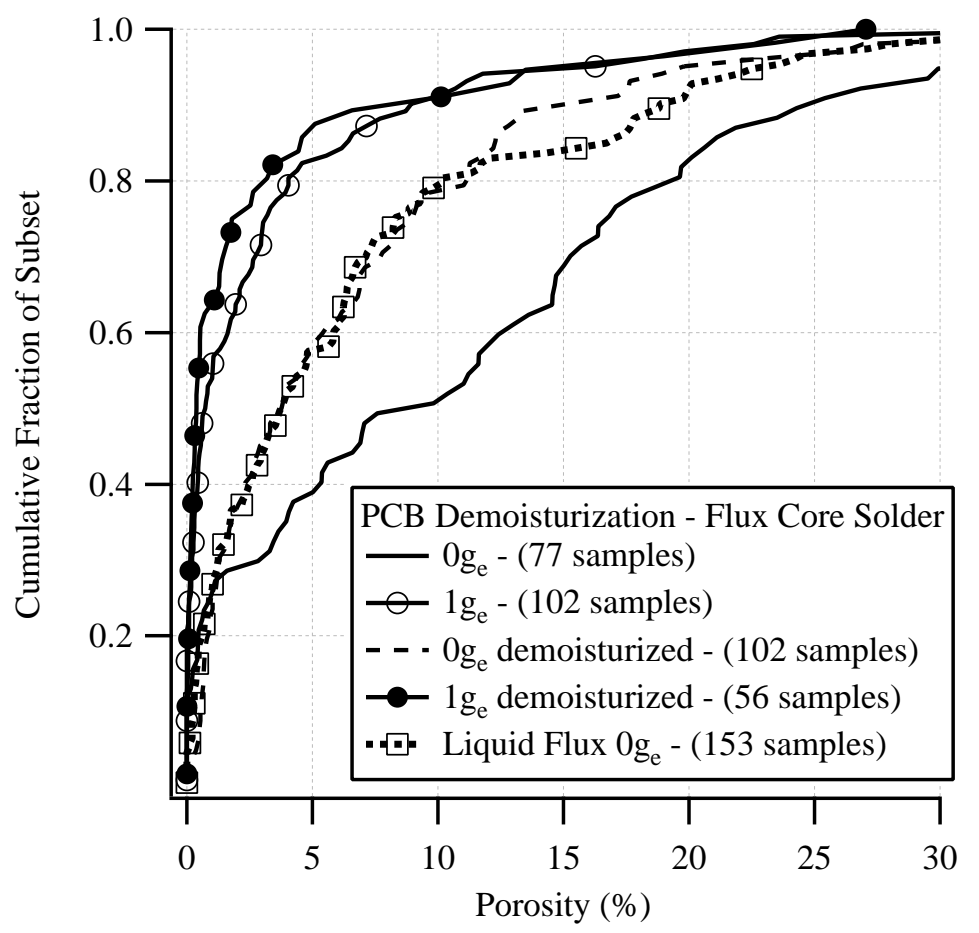

Fig. 7 Cumulative distribution function plot showing influence of moisture removal in PCBs by baking at $93 \mathrm{C}$ for 4 hours

during our tests. PCBs stored in this normal room environment eventually regained $33 \%$ of their lost mass after 7 days. The humidity levels aboard the KC- $135^{* *}$ are typically lower than the normal room environment indicating that we were, in fact, soldering demoisturized boards during our experiment. As a corollary to this test, we exposed baked PCBs to $100 \%$ relative humidity. These boards regained $\sim 14 \%$ of their lost mass within 20 minutes. The boards stored in a saturated (100\% relative humidity) environment eventually gained up to 0.090 grams of mass (or $251 \%$ of their lost mass). This suggests that mass lost during the demoisturization process can be replaced (or even exceeded) with water absorbed from the surrounding environment.

PCB bake-out does reduce the overall porosity of the joint (Fig. 7). Included in this figure, for comparison, are the cumulative distribution functions for samples produced with conventional flux-cored solder. Examination of solder joints made with demoisturized PCBs shows that the positive effect on porosity reduction achieved by removing moisture from the boards is similar to those achieved using the liquid flux which is also included in Fig 7.

\section{Pores size distribution as a function of g-level.}

Data for the average pore diameter and the average number of pores seen in sample cross-sections are presented in Table 4. We were able to resolve pore diameters as small as $\sim 0.012 \mathrm{~mm}$. The uncertainty of the mean pore diameter in Table 4 represents a 95\% confidence interval on the mean value. Pore diameters are stated as they appear in cross section images. Due to the arbitrary location of the cross-sectioning plane with respect to the internal pores, the true pore diameters are almost certainly larger than they appear, except in the unlikely event that a joint's cross section image coincides exactly with the center of a pore. While the relationship between apparent and actual pore diameter is not readily quantifiable, it is assumed that for large sample populations this effect acts similarly on each population. Thus, the resulting numbers are only useful for comparison with other sample populations and do not represent accurate pore diameter measurements.

Similarly, it is unlikely that every pore in a joint would be visible in a single cross section. Using the same argument stated above, it is assumed that these results are useful for comparison among different subsets of data, but do not likely represent the actual number of pores in a given joint.

The data in Table 4 shows that pore diameters, on average, are smaller in $1-g_{e}$ when compared with 0 -ge. Also, the number of pores per joint decreases in $1-g_{e}$ when compared to $0-g_{e}$. This reduction is also apparent in the confidence intervals, which increase for 1-ge. The reduced number of pores per joint for the 1-ge samples is likely due to buoyant forces which have expelled a significant number of bubbles. Similarly, the larger bubbles in 1 -ge are more likely to reach a free-surface owing to their larger buoyantly induced velocity.

\footnotetext{
${ }^{* *}$ For the 0 -ge samples, the average recorded relative humidity in the glovebox was $26.6 \%$ with a standard deviation of $11.1 \%$ (651 samples). For the 1-ge samples, the average recorded relative humidity in the glovebox was $51.6 \%$ with a standard deviation of $18 \%$ (227 samples). Please note that the relative humidity was a manual measurement and was not recorded for every sample.
} 
Table 4 Pore size distribution as a function of g-level and soldering condition

\begin{tabular}{l|ccc|ccc|}
\hline \hline \multirow{2}{*}{ Condition } & \multicolumn{3}{|c|}{0 - $_{\mathrm{e}}$} & \multicolumn{3}{c|}{1 -ge } \\
\cline { 2 - 6 } & $\begin{array}{c}\text { Mean Pore } \\
\text { Diameter (mm) }\end{array}$ & $\begin{array}{c}\text { Mean Pores } \\
\text { per Joint }\end{array}$ & Samples & $\begin{array}{c}\text { Mean Pore } \\
\text { Diameter (mm) }\end{array}$ & $\begin{array}{c}\text { Mean Pores } \\
\text { per Joint }\end{array}$ & Samples \\
\hline Flux-core & $0.108 \pm 0.005$ & 18.0 & 77 & $0.070 \pm 0.007$ & 6.5 & $102^{*}$ \\
$\begin{array}{l}\text { Solid-core / } \\
\text { liquid flux }\end{array}$ & $0.103 \pm 0.005$ & 13.1 & 153 & $0.069 \pm 0.005$ & 8.5 & $111^{*}$ \\
$\begin{array}{l}\text { Solid-core / gel- } \\
\text { flux }\end{array}$ & $0.097 \pm 0.007$ & 21.1 & 43 & $0.066 \pm 0.009$ & 11.9 & $32^{*}$ \\
$\begin{array}{l}\text { Flux-core / } \\
\text { baked board }\end{array}$ & $0.088 \pm 0.006$ & 11.2 & 102 & $0.073 \pm 0.011$ & 5.8 & $56^{*}$ \\
\hline \hline
\end{tabular}

* Includes 1-g samples soldered on the ground and at altitude (0.08-0.09 MPa cabin pressure)

\section{Correlation of visual inspection results with measured porosity.}

External visual inspection is the only method of quality assurance currently available to crewmembers. Consequently, verifying the effectiveness of using external inspection to determine internal qualities of soldered connections is of relevance to this undertaking. To determine whether visual inspection is an adequate indicator of internal solder joint quality, internal porosity metrics (average volume percent porosity, average pore diameter, and average number of pores per joint) were tabulated for groupings of visual inspection results. Samples from all soldering process variations (flux core solder, liquid flux, gel flux and baked boards) were grouped together under the assumption that the relationship between external appearance and measured porosity would be independent of solder/flux type. The results of this comparison are presented in Table 5. The uncertainties in the tabulated results reflect statistical confidence intervals at the 95\% confidence level.

The data in Table 5 shows that all 0 -g $_{\mathrm{e}}$ subsets had (on average) greater porosity, larger average pore diameters, and increased number of pores per joint than the respective $1-g_{e}$ subset although low-sample numbers in some cases make the $95 \%$ confidence intervals high. Within the 0 -ge subset, samples that failed the inspection due to surface porosity had significantly higher porosity values and average pore diameters than either of the other two groups of 0 -ge samples. The same can be said of the $1-g_{e}$ samples, although the low number of failing joints due to surface porosity (21) resulted in large confidence intervals (hence greater uncertainty) for that condition. Interestingly, the 0 -ge subset of samples which passed the visual inspection had joint porosity values similar (statistically) to those which failed the visual inspection in 1-ge. A reasonable explanation for this is that the bubbles in the 0 -g g $_{\mathrm{e}}$ samples are moving at very low velocities and, thus, are predominantly located in the interior of the joint at the time of solidification. In contrast, the bubbles in the $1-\mathrm{g}_{\mathrm{e}}$ samples are moving rapidly towards the free surface so that those which remain at the time of solidification are more likely to be at or near the surface. Nonetheless, the generalization can be made that on average, samples with external indications of internal porosity (cavities, pinholes, bulges, etc.) have higher porosity than samples lacking these indications. Thus, a visual inspection can be a useful tool (particularly because of its inherent simplicity) to determine whether a solder joint contains excess porosity.

Table 5 Joint porosity characteristics sorted by visual inspection results; all soldering conditions represented.

\begin{tabular}{c|c|c|c|c|c}
\hline \hline \multirow{2}{*}{ g-level } & Data subset & Samples & $\begin{array}{c}\text { Average } \\
\text { porosity (\%) }\end{array}$ & $\begin{array}{c}\text { Average pore } \\
\text { diameter (mm) }\end{array}$ & $\begin{array}{c}\text { Average } \\
\text { pores/joint }\end{array}$ \\
\hline \multirow{3}{*}{$\mathbf{o g}_{\boldsymbol{e}}$} & Passed visual inspection & 293 & $7.24 \pm 0.92$ & $0.097 \pm 0.003$ & $14.0 \pm 1.6$ \\
\cline { 2 - 6 } & Failed - Workmanship & 20 & $5.42 \pm 3.64$ & $0.089 \pm 0.016$ & $9.8 \pm 4.4$ \\
\cline { 2 - 6 } & Failed - Surface Porosity & 62 & $11.76 \pm 2.42$ & $0.113 \pm 0.007$ & $18.2 \pm 4.0$ \\
\hline \multirow{2}{*}{$\mathbf{1}-g_{\boldsymbol{e}}$} & Passed visual inspection & 246 & $2.91 \pm 0.60$ & $0.067 \pm 0.004$ & $8.2 \pm 1.4$ \\
\cline { 2 - 6 } & Failed - Workmanship & 34 & $1.76 \pm 0.87$ & $0.075 \pm 0.015$ & $4.6 \pm 1.7$ \\
\cline { 2 - 6 } & Failed - Surface Porosity & 21 & $5.88 \pm 3.56$ & $0.105 \pm 0.021$ & $7.1 \pm 2.7$ \\
\hline \hline
\end{tabular}




\section{Pressure effects.}

To assess the potential influence of reduced aircraft cabin pressure when soldering at altitude, we compared datasets for two sets of soldering conditions: those produced onboard the aircraft while it was aloft at a nominal acceleration value of $1-\mathrm{g}_{\mathrm{e}}$ and while it was stationary on the ground. The atmospheric pressure of the aircraft cabin, while flying, is maintained at the equivalent of that at approximately 2400 meters altitude $(0.08-0.09 \mathrm{MPa})$. The mean number of pores and the mean apparent pore diameter were determined for the sample sets. Results are shown in Table 6.

Table 6 Influence of altitude and cabin pressure on internal porosity in normal gravity

\begin{tabular}{|c|c|c|c|c|}
\hline & Condition & $\begin{array}{c}\text { Number of } \\
\text { Samples }\end{array}$ & $\begin{array}{l}\text { Mean Number of } \\
\text { Pores (+95\% CI) }\end{array}$ & $\begin{array}{c}\text { Mean Pore } \\
\text { Diameter } \pm 95 \% \\
\text { CI, } \mathbf{m m} \\
\end{array}$ \\
\hline \multirow{2}{*}{ Flux-core solder } & Ground* & 70 & $6.4 \pm 2.3$ & $0.069 \pm 0.009$ \\
\hline & Altitude** & 32 & $6.7 \pm 2.2$ & $0.073 \pm 0.01$ \\
\hline \multirow{2}{*}{$\begin{array}{l}\text { Solid-core } \\
\text { liquid flux }\end{array}$} & Ground* & 103 & $8.8 \pm 2.7$ & $0.068 \pm 0.005$ \\
\hline & Altitude** & 8 & $5.0 \pm 3.9$ & $0.109 \pm 0.038$ \\
\hline \multirow{2}{*}{$\begin{array}{l}\text { Solid-core solder, gel } \\
\text { flux }\end{array}$} & Ground* & 16 & $10.4 \pm 3.1$ & $0.066 \pm 0.015$ \\
\hline & Altitude** & 16 & $13.5 \pm 8.3$ & $0.067 \pm 0.013$ \\
\hline \multirow{2}{*}{$\begin{array}{l}\text { Flux-core solder, } \\
\text { demoisturized boards }\end{array}$} & Ground* & 24 & $3.3 \pm 1.0$ & $0.073 \pm 0.021$ \\
\hline & Altitude** & 32 & $7.6 \pm 2.2$ & $0.073 \pm 0.010$ \\
\hline
\end{tabular}

* soldering performed on ground at atmospheric pressure of approximately $0.10 \overline{\mathrm{MPa}} \overline{\text {. }}$

** soldering performed while aircraft at altitude with a cabin pressure of $0.08-0.09 \mathrm{MPa}$.

The data indicate that, in general, for both soldering conditions, the mean number of pores is greater when soldering occurred at the reduced pressure experienced during flight. However, since the sample populations examined were rather small and that the confidence intervals are commensurately large, a firm conclusion that reduced pressure increases number of pores is not possible. It is possible that reduced pressure has a positive effect on nucleation of bubbles forming from moisture originating in the PCB laminate. The presence of flux from which flux-based pores form should be independent of ambient pressure. The data suggest that the ambient pressure does not have a significant effect on average pore diameter.

\section{Cooling Rate}

The crewmember who conducted the manual soldering experiment aboard STS-57 in 1993 reported to the authors that the solidification time appeared to be longer for joints soldered in microgravity (compared to those he soldered on Earth while training). If this observation is correct, then the likely reason for this difference is the lack of buoyancy-driven convection available to contribute to heat loss from the exposed surface of the solder joint. To help understand any differences in cooling rate, we instrumented several of our solder samples with small type $\mathrm{K}$ thermocouples ( $0.051 \mathrm{~mm}$ diameter wire and $\sim 0.17 \mathrm{~mm}$ beads). The thermocouples, which were spot welded to the metal pad on the surface of the PCB, recorded temperature data during the soldering process (Fig. 8). A small number of these instrumented samples included a second thermocouple at another location. The purpose of this additional thermocouple was to determine if temperature gradients existed across a joint; the resultant data (not shown) indicates that the temperature of these joints was essentially spatially uniform. Using these data, the temperature profiles and heat transfer rates in both reduced gravity and normal gravity environments were analyzed and compared statistically. In Fig. 8, the vertical lines on the chart correspond to events in the soldering process as labeled. These times were determined from the videos. Note that the right-most vertical line corresponds to when the joint is completely solidified, which was visually manifested in the videos as a change in luster. The joint temperatures measured by thermocouple correlated well with the observations of soldering events on the video data (e.g. heat application, heat removal, and solidification). 


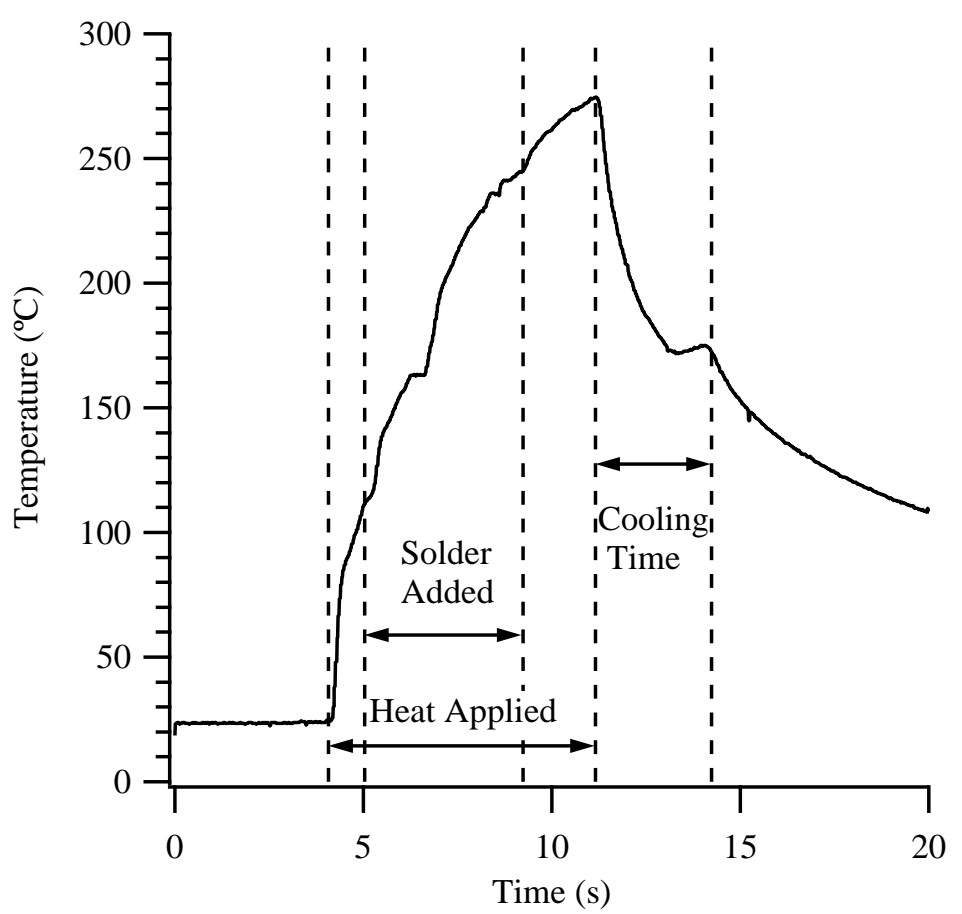

Fig. 8 Typical thermocouple and video data plot for the soldering process. The dashed lines represent soldering events as determined from the videos.

As the time required for a joint to solidify depends on several factors (such as joint mass and peak temperature), a comparison of cooling time only is not meaningful. Rather, the average rate of heat transfer during the cooling period is computed for each joint as follows. The total thermal energy lost by the solder in the course of cooling from the peak temperature through solidification is shown in Eq. (2). This equation assumes that the joint temperature is spatially uniform and that the specific heat is independent of temperature. The thermophysical properties are listed in the nomenclature. In Eq. (2), the mass of the solder joint was determined by weighing the solder feed wire before and after soldering.

$$
\left.Q=m C_{p} T_{p}-T_{m}\right)+m h_{f}
$$

To determine the average heat transfer rate from the solder joint, the total energy is simply divided by the cooling time as shown in Eq. (3). The cooling time was determined from data like that shown in Fig. 8 and represents the time from solder iron removal to complete joint solidification (as determined from the end of the plateau region seen in the figure).

$$
\dot{Q}_{a v}=\frac{Q}{t_{c}}
$$

The results of this computation are given below (Table 7) in the form of an average heat transfer rate across all instrumented samples for each data subset. The computation of the confidence intervals assumes a t-student distribution. 
Table 7 Average overall heat transfer rates for normal and reduced gravity subsets.

\begin{tabular}{cccc}
\hline \hline & $\begin{array}{c}\text { Number of } \\
\text { samples }\end{array}$ & $\begin{array}{c}\text { Average heat transfer rate } \\
(\boldsymbol{\mu} \pm \mathbf{9 5 \%} \mathbf{C I})\end{array}$ & $\begin{array}{c}\text { Average heat transfer rate } \\
(\boldsymbol{\mu} \pm \mathbf{6 0} \% \mathbf{C I})\end{array}$ \\
\hline Low-g & 31 & $0.67 \pm 0.09 \mathrm{~W}$ & $0.67 \pm 0.04 \mathrm{~W}$ \\
\hline $\mathbf{1 - g}$ & 25 & $0.75 \pm 0.11 \mathrm{~W}$ & $0.75 \pm 0.05 \mathrm{~W}$ \\
\hline \hline
\end{tabular}

The data in Table 7 shows that the heat transfer from the solder joints is slightly slower in 0 -g than in $1-g_{e}$. This supports the idea that joints will take longer to solidify in reduced gravity due to a lack of natural convection. Due to small sample populations and consequently large confidence intervals, though, it cannot be said that the joint cooling rates are statistically different in reduced gravity above a calculated confidence level of $60 \%$. Nevertheless, if the nominal average heat transfer rates truly are representative, then the solidification time of 0 -g $\mathrm{g}_{\mathrm{e}}$ and $1-\mathrm{g}_{\mathrm{e}}$ samples of the same mass would be approximately $10 \%$, or slightly less than 0.5 seconds. Although this is a fairly small difference, it would be visually detectable and could account for the observation of the STS-57 crewmember.

\section{E. Leg-length geometry}

In a previous paper ${ }^{17}$, we have demonstrated that geometrical differences exist in solder joints produced in reduced gravity, as compared to those formed in normal gravity. The most significant results are repeated here for completeness. A measure of the joint geometry is the ratio of leg lengths, $\mathrm{L}_{\mathrm{T}}$ (top leg) to $\mathrm{L}_{\mathrm{B}}$ (bottom leg), as shown in Fig. 2a. The leg lengths were measured using digitized, magnified images of the complete solder joint (prior to cross-sectioning). The resulting mean leg length ratios for various test conditions are shown in Table 8. The uncertainty listed in Table 8 reflects a 95\% confidence interval on the mean value assuming a t-student distribution for the leg-length ratio data set and the individual measurement uncertainties of each sample $( \pm 0.02 \mathrm{~mm})$. More details regarding the dataset are in the references ${ }^{17}$.

Table 8. Mean leg-length ratios for a given combination of flux type and acceleration level.

\begin{tabular}{ccccc}
\hline \hline \multirow{2}{*}{ Test Condition } & \multicolumn{2}{c}{$\mathbf{1 - g _ { \mathbf { e } }}$} & \multicolumn{2}{c}{$\mathbf{0 - \mathbf { g } _ { \mathbf { e } }}$} \\
& Samples & $\mathbf{L}_{\mathbf{T}} / \mathbf{L}_{\mathbf{B}}$ & Samples & $\mathbf{L}_{\mathbf{T}} / \mathbf{L}_{\mathbf{B}}$ \\
\hline Flux Core Solder & 222 & $0.76 \pm 0.03$ & 381 & $1.08 \pm 0.04$ \\
\hline Solid Core Solder \& Liquid Flux & 91 & $0.71 \pm 0.10$ & 198 & $1.16 \pm 0.04$ \\
\hline \hline
\end{tabular}

While normal gravity joints have mean leg-length ratios significantly less than unity, the same ratio for reduced gravity joints tend to slightly exceed unity. The trends held similarly for both the flux cored solder, and with solid solder along with liquid flux. The hypothesized reason for this change in geometry is that there is insufficient time or driving force to transport of solder from the top to the bottom of the joint in 0 -ge. However, other effects such as bubble evolution, mass added, and solder application technique tend to confound the joint equilibration.

\section{Conclusion}

Experimental efforts have demonstrated that manual soldering is a viable process for repair of electronic systems as an element of in-flight maintenance capabilities. Although the reduced gravity environment introduces some new issues, these can be accommodated by appropriate application of modified processes and alternative materials used in the soldering process. Specific findings of this study are enumerated below.

1. Solder joints produced in a 0 -ge $_{e}$ environment with conventional soldering techniques (utilizing solder wire with a flux core) typically exhibit significantly higher levels of porosity than joints soldered in a 1-ge environment.

2. Sources of porosity in solder joints include flux which vaporizes to form bubbles and moisture that is evolved from the PCB laminate. In a 0 -g environment the lack of buoyant forces results in slower bubble transport and eventual entrapment as pores upon freezing of the solder alloy.

3. Porosity resulting from evolved moisture can be reduced by baking of the boards prior to soldering. Under operational circumstances in spaceflight environments, however, this may not be easily accomplished. 
4. Porosity arising from entrapped flux can be reduced significantly by implementation of an alternative procedure utilizing a liquid flux that is applied to the joint followed by heating with the soldering iron to activate and evaporate the flux, and subsequent application of a solid solder wire (no flux core).

5. Visual inspection was shown to be somewhat indicative of joint porosity, but joints made in reduced gravity can pass a visual inspection and still have high levels of internal porosity.

6. The experimental results suggest a very small decrease in heat transfer rate for samples soldered in the 0-ge environment compared to those soldered in 1-ge, but the difference is difficult to distinguish statistically. Conceptually, a small difference would be expected because of the lack of convective cooling by the ambient environment.

7. Solder joints produced in a 0 -ge environment are more geometrically symmetric than joints produced in a 1 -ge environment.

8. The quality of manual soldering of plated-through-hole configurations is not highly contingent upon operator skill levels. Operators with minimal training and experience can perform comparably to operators with much more extensive experience.

\section{Acknowledgments}

This study was part of the Research for Design Program of the National Center for Microgravity Research. This program is funded by NASA's Office of Biological and Physical Research. Additional funding was provided by NASA's International Space Station Program Office. The authors would like to thank the following individuals for their valuable contributions to this project: Gregory Fedor, Jack Kolis, Michael Dobbs, James Withrow, Anthony Butina, Michael Conley, Robert Lowe, William O’Hara, Edward Van Cise, Allison Bahnsen, Owen Farmer, Julio Estrada and the crew of the NASA KC-135 research aircraft.

Trade names or manufacturers' names are used in this report for identification only. This usage does not constitute an official endorsement, either expressed or implied, by the National Aeronautics and Space Administration.

\section{References}

1) ASM, "Properties and Selection: Nonferrous Alloys and Special-Purpose Materials," Metals Handbook, 10th Ed., Vol.2, ASM International, 1990.

2) ASM, "Welding, Brazing, and Soldering”, Metals Handbook, ASM International, 10th ed., Vol.6, 1990.

3) ASM, ASM Metals Reference Book, $3^{\text {rd }}$ ed., Michael Bauccio, Ed. ASM International, Materials Park, OH, 1993.

4) Carlberg, T. and Liljendahl, M., "Soldering Under Microgravity," Proceedings of the 4th European Symposium on Materials Sciences under Microgravity, ESA SP-191, 1983, pp. 337 - 342.

5) Winter, C.A. and J.C. Jones, “The Microgravity Research Experiments (MICREX) Database”, NASA TM-108523, Vol. 4, Nov. 1996.

6) EDSYN, Inc., “NASA Payload No. 88 - STS-7”, 1983.

7) Jones, J.C. and deRooij, A., "Preliminary Investigation of Soldering Electronic Components in Zero-Gravity”, E.W.P. 1554, European Space Agency, 1989.

8) Kacpura, T.J. and Acevedo, J.C., "Space acceleration measurement system for free flyers (SAMS-FF) - Initial test results," AIAA Paper 1998-454, Jan. 1998.

9) Struk, P.M., Pettegrew, R.D., Downs, R.S., and Watson, J.K., "The Effects of an Unsteady Reduced Gravity Environment on the Soldering Process,” AIAA Paper 2004-1311 and NASA TM-2004-212946, Jan. 2004.

10) NASA, "Soldered Electrical Connections," NASA-STD-8739.3, Dec. 1997.

11) Pettegrew, R.D., Struk, P.M., Watson, J.K., and Haylett, D.R., "Experimental Methods in Reduced-Gravity Soldering Research,” NASA TM-2002-211993, Dec. 2002.

12) Pettegrew, R.D., Struk, P.M., Watson, J.K., Haylett, D.R., and Downs, R..S., “Gravitational Effects on Solder Joints,” Welding Journal, Vol. 82, No. 10, Oct. 2003, pp. 44-48.

13) ASTM Committee E-4, "Standard Practice for Determining the Inclusion or Second-Phase Constituent Content of Metals by Automatic Image Analysis,” Annual Book of ASTM Standards 2001, Sect. 3, Vol. 03.01, 2001.

14) European Space Agency (ESA),” Some Experiment Results from the SPFC 2003”

URL: http://www.estec.esa.nl/outreach/parabolic/results 2003 frame.htm, [cited 28 October 2005].

15) Seah, M.P., F.H. Howie, and C. Lea. "Blowholing in PTH Solder Fillets, Part 3: Moisture and the PCB”, Circuit World, Vol. 12, No. 4, 1986, pp. 26 - 33.

16) Howie, F.H. and Lea, C., "Blowholing in PTH Solder Fillets, Part 2: The Nature, Origin and Evolution of the Gas", Circuit World, Vol. 12, No. 4, 1986, pp. $20-25$.

17) Struk, P.M., Pettegrew, R.D., Downs, R.S., and Watson, J.K., “The Influence of Gravity on Joint Shape for ThroughHole Soldering,” AIAA Paper 2005-0541 and NASA TM-2005-213589, Jan. 2005. 